\title{
Ensuring effective financing of national blood systems in support of universal health coverage
}

Yetmgeta Abdella, ${ }^{1}$ Awad Mataria, ${ }^{2}$ Fatma Sajwani, ${ }^{3}$ Ali Akbar Pourfathollah, ${ }^{4}$ and Cees Th. Smit Sibinga ${ }^{5}$

${ }^{1}$ Medical Officer, Blood and Transfusion Safety, Department of Communicable Diseases Control, World Health Organization, Regional Office for the Eastern Mediterranean, Cairo, Egypt. ${ }^{2}$ Regional Adviser, Health Economics and Financing, Department of Health System Development, World Health Organization, Regional Office for the Eastern Mediterranean, Cairo, Egypt. ${ }^{3}$ Medical Director, Sharjah Blood Transfusion \& Research Center (WHO Collaborating Centre for Training and Research in Blood Transfusion), Sharjah, United Arab Emirates. ${ }^{4}$ Director, High Institute of Research and Education in Transfusion Medicine, Iranian Blood Transfusion Organization, (WHO Collaborating Centre for Research \& Training on Blood Safety), Tehran, Islamic Republic of Iran. ${ }^{5}$ Director, International Quality Management (IQM) Consulting and Professor of International Development of Transfusion Medicine, Zuidhorn, The Netherlands. (Correspondence to: Yetmgeta Abdella: abdellay@who.int).

Citation: Abdella Y; Mataria A; Sajwani F; Pourfathollah AA; Smit Sibinga CT. Ensuring effective financing of national blood systems in support of universal health coverage. East Mediterr Health J. 2019;25(6):371-373. https://doi.org/10.26719/2019.25.6.371

Copyright (C) World Health Organization (WHO) 2019. Some rights reserved. This work is available under the CC BY-NC-SA 3.0 IGO license (https:// creativecommons.org/licenses/by-nc-sa/3.o/igo).

In 2012 the United Nations (UN) General Assembly adopted Resolution 67/81 on Global Health and Foreign Policy whereby all Member States agreed to work towards achieving Universal Health Coverage (UHC), which was later included as one of the targets of the UN Sustainable Development Goals (SDGs) 2016-2030 (1,2). The Resolution reaffirms, "the right of every human being to the enjoyment of the highest attainable standard of physical and mental health, without distinction including economic or social condition."

Universal Health Coverage (UHC) means that all people and communities should be able to use the health services they need, of sufficient quality to be effective, while also ensuring that the use of these services does not expose the user to financial hardship (3). It embodies three related objectives:

1. Equity in access to health services - everyone who needs services should get them, not only those who can afford and pay for them;

2. the quality of health services should be good enough to improve the health of those receiving them; and

3. people should be protected against financial hardship, ensuring that the cost of using services does not put people at risk of financial ruin or poverty.

The 2017 UHC Global Monitoring Report estimated that half of the world population does not have access to needed health care and that 100 million people are impoverished every year while seeking needed health services (4). This fundamental right remains a distant goal, especially for children and those living in poverty.

Regarding blood and blood products, UHC means that all individuals and communities need to have access to affordable and timely supplies of safe, qualityassured and efficacious blood and blood products, with financial protection $(5,6)$. However, inadequate access to blood and blood products remains a challenge in countries in the WHO Eastern Mediterranean Region (7). In addition, excessive out-of-pocket payments can discourage people from seeking needed safe blood and blood products, or push them into poverty in their attempts (1). Despite efforts during the last four decades, only limited attention has been given by governments to establishing sustainable financing arrangements, effective governance mechanisms, adequate health workforce, essential technologies, and functioning health information systems to ensure equitable access to safe blood and blood products.

It should be noted that there is a strong relation between health and the economy, whereby the containment of the burden of disease leads to improved productivity of people, contributing to the overall economy $(8,9)$. The 2016 report "High-Level Commission on Health Employment and Economic Growth" (10) identifies six pathways through which health systems could contribute to economic growth, besides their contribution to global security, education, gender equality, and other development goals (10). Ensuring effective access to blood and blood products, besides being a right, is key for development.

Differences prevail between countries in how blood and blood products are financed. In many upper-middle, high or very high-income countries patients are not directly charged, while some low and lower-middle income economies still charge patients totally or partially for the costs of blood and blood products (11). Providing access to affordable and timely supplies of safe, qualityassured and efficacious blood and blood products is a continuum. The principles of access to health and related care are spelled out in the 1948 UN Declaration of Universal Human Rights (12). However, it requires concerted efforts of responsible ministries, such as finance, public health and education, to realize that these principles are constitutionally anchored in appropriate legislative and regulatory frameworks overseen by a competent National Regulatory Authority (NRA) (7,13).

Ensuring access does need adequate financing, where recovery of the essential costs and investments is achieved. In fact, provision of safe and efficacious blood, blood products as well as plasma derived medicinal 
products (PDMP), e.g. clotting factor concentrates, immunoglobulins and albumin, could be provided 'free of charge'. However, the costs to provide such products need to be recovered, for example through effective prepayment arrangement, by ensuring their inclusion in the publicly funded national package of health services (14). If such a principle were to be implemented effectively, the national burden of disease and the patient qualityadjusted life years (QALYs) gained would dramatically improve with lower healthcare expenditures $(15,16)$.

There is no debate on the need for establishing a financing system based on a proper and realistic analysis of the costs needed to provide the required services and quality products. These split into two main categories - capital, and recurrent investments/costs. For each category, finances need to be allocated and sustained to allow permanent quality services to be provided to every citizen in need, irrespective of economic and social conditions. Capital investment is not only facilities, equipment and vehicles, but more importantly the competence of the human resource - education through appropriate and timely teaching (vocational and academic), and training for technical skills to allow high standard practical health care operations, e.g. promotive, preventive, diagnostic, curative, rehabilitative and palliative health interventions and services.

Evidence is needed to ensure result-oriented financing and payment arrangements as part of the national health system, whether public or private (17). Budgeting should be based on cost analysis; payment arrangements through social security, taxes and insurance system, or mixed sources, should recover essential costs and investments on a non-for-profit basis (18). The costing needs to be done without jeopardizing the necessary investments needed for a consistent quality output of the services and operations, e.g. excessive overheads in case of too small economies of scale, and sustained fragmentation of the blood supply. A recent survey done by the WHO Regional Office for the Eastern Mediterranean revealed that shortcomings in financing the blood system was one of the four top challenges in the Region (19). The existence of an effective financing system will especially protect poor people against the financial risks of ill health by limiting out-of-pocket payments $(9,18)$.

\section{References}

1. United Nations. Resolution 67/81 Global Health Policy. New York: United Nations; 2012 (https://undocs.org/A/RES/67/81).

2. United Nations. Sustainable Development Goals. New York: United Nations; 2015. (https://sustainabledevelopment. un.org/?menu=1300).

3. World Health Organization. Arguing for Universal Health Coverage. Geneva: World Health Organization; 2013 (https://www.who. int/health_financing/UHC_ENvs_BD.PDF?ua=1).

4. World Health Organization. Tracking Universal Health Coverage. 2017 Global Monitoring Report. Geneva: World Health Organization; 2017 (http://pubdocs.worldbank.org/en/193371513169798347/2017-global-monitoring-report.pdf).

5. World Health Organization. World Health Day 2018: Universal Health Coverage: everyone, everywhere. Geneva: World Health Organization; 2018. (http://www.emro.who.int/media/news/world-health-day-2018-universal-health-coverage-everyoneeverywhere.html).

6. World Health Organization. Draft thirteenth general programme of work 2023-2019. Geneva: World Health Organization; 2018 (http://apps.who.int/gb/ebwha/pdf_files/EB142/B3_142Rev-2en.pdf).

7. Abdella Y, Akbar Pourfathollah A, Slama H, Raouf M. The role of access to affordable and quality assured blood and blood products for achieving Universal Health Coverage. East Mediterr Health J. 2018;24(3):235-236.

8. World Health Organization. Health Financing Guidance No 3. Developing a national health financing strategy: a reference guide. Geneva: World Health Organization; 2017 (https:/apps.who.int/iris/bitstream/handle/10665/254757/9789241512107-eng. pdf?sequence=1).

9. World Health Organization. Together on the road to universal health coverage. A call to action. Geneva: World Health Organization; 2017. (https://apps.who.int/iris/bitstream/handle/10665/258962/WHO-HIS-HGF-17.1-eng.pdf?sequence=1).

10. World Health Organization. Final report of the expert group to the High-Level Commission on Health Employment and Economic Growth. Geneva: World Health Organization; 2016 (https://apps.who.int/iris/bitstream/hand le/10665/250040/9789241511285-eng.pdf;jsessionid=157173189D059DBB160843872923FFoo?sequence=1).

11. Divkolaye N, Seighali F, Akbar Pourfathollah A, Smit Sibinga CT. A country-wide comparison of cost-recovery and financing systems of blood and blood products. East Mediterr Health J. 2019;25:104-10.

12. United Nations. Universal Declaration of Human Rights. New York: United Nations; 2015 (https://www.un.org/en/udhrbook/pdf/ udhr_booklet_en_web.pdf).

13. Smit Sibinga CT, Abdella YE, Konings F. Review of existing legislative instruments for blood systems of countries in the WHO Eastern Mediterranean Region. Global J Transfus Med 2019;4:6-15

14. World Health Organization. World Health Report 2010. Health systems financing. The path to universal coverage. Geneva: World Health Organization; 2010 (https://apps.who.int/iris/bitstream/handle/10665/44371/9789241564021_eng.pdf;jsessionid=A17DFB80 5404ED461D3EE42EE04EB6E1?sequence=1). 
15. Custer B. Economic analyses of blood safety and transfusion medicine interventions: a systematic review. Transfus Med Rev 2004;18:127-43

16. Van Hulst M. Health Economics of Blood Transfusion Safety. Academic PhD thesis, University of Groningen, Groningen, Netherlands, 2008.

17. Mathaur I, Dkhimi F. Analytical guide to assess a mixed provider payment system. A guidance document. Department of Health Systems Governance and Financing. Geneva: World Health Organization; 2018 9WHO/UHC/HGF/GUIDANCE/19.5)

18. Kutzin J, Yip W, Cashin Ch. Alternative financing strategies for Universal Health Coverage. World Scientific Series in Global Health Economics and Public Policy - World Scientific Handbook of Global Health Economics and Public Policy, 2016:267-309 (https://www.worldscientific.com/doi/pdf/10.1142/9789813140493_0005).

19. Abdella YE, Hajjeh R, Smit Sibinga CT. Availability and safety of blood transfusion during humanitarian emergencies. East Mediterr Health J. 2018;24;796-806 